\title{
Ginkgolic acids induce HepG2 cell death via a combination of apoptosis, autophagy and the mitochondrial pathway
}

\author{
QIAN-MING QI ${ }^{1}$, YIN-CUN XUE ${ }^{2}$, JIAN LV $^{2}$, DI SUN ${ }^{2}$, JIAN-XIN DU $^{2}$, SHENG-QIANG CAI $^{2}$, \\ YUN-HE $\mathrm{LI}^{2}$, TIAN-CUN GU ${ }^{2}$ and MU-BING WANG ${ }^{2}$ \\ ${ }^{1}$ Department of Medical Laboratory, The 359th Hospital of The People's Liberation Army, Zhenjiang, Jiangsu 212000; \\ ${ }^{2}$ Department of General Surgery, Jingjiang People's Hospital, Taizhou, Jiangsu 214500, P.R. China
}

Received November 8, 2016; Accepted January 12, 2018

DOI: $10.3892 / \mathrm{ol} .2018 .8177$

\begin{abstract}
Ginkgolic acids may induce malignant cell death via the $\mathrm{B}$-cell lymphoma 2 ( $\mathrm{Bcl}-2)$-associated $\mathrm{X}$ protein $(\mathrm{Bax}) / \mathrm{Bcl}-2$ apoptosis pathway. Concurrently, apoptosis, autophagy and mitochondrial dysfunction may also be involved in bringing about this endpoint. The anticancer effect of Ginkgolic acids (GAs) was investigated using the HepG2 cell line. The median lethal dose of the GAs of the HepG2 was measured via an MTT assay, the dose-response curves were evaluated and changes in cell morphology were monitored by microscopy. Autophagy in HepG2 cells was down regulated using 3-methyladenine (3-MA) or Beclin-1-specific small interfering RNA (siRNA) and the expression of apoptosis associated proteins caspase-3, $\mathrm{Bax} / \mathrm{Bcl}-2$, and the autophagy-associated protein 5 and microtubule-associated protein 1A/1B-light chain 3 in the GA-treated HepG2 cells were all measured by western blot analysis. The level of apoptosis in the GA-treated cells was also assessed using terminal deoxynucleotidyl-transferase-mediated dUTP nick-end labeling (TUNEL) assay, and the mitochondrial membrane potential $\left(\Delta \psi_{\mathrm{m}}\right)$ was detected by immunofluorescence. The results of the MTT and TUNEL assays indicated that the proliferation of HepG2 cells treated with GAs was significantly reduced compared with the control group, and the rate of the inhibition was dose-dependent. Western blot analysis indicated that treatment with the Gas induced apoptosis and autophagy in the HepG2 cells. The $\Delta \psi_{\mathrm{m}}$ of the GA-treated HepG2 cells was decreased compared with the control, as monitored by immunofluorescence. However, upon the administration of 3-MA or Beclin-1-specific siRNAs (inhibitors of the autophagy), the expression levels of the apoptosis- and autophagy-associated proteins were
\end{abstract}

Correspondence to: Dr Mu-Bing Wang, Department of General Surgery, Jingjiang People's Hospital, 28 Zhongzhou Road, Taizhou, Jiangsu 214500, P.R. China

E-mail: wangmubin2007@163.com

Key words: autophagy, apoptosis, mitochondrial dysfunction, ginkgolic acids, HepG2 cells decreased. In conclusion, the results of the present study indicated that GAs are potent anticancer agents that function through a combination of the apoptosis, autophagy and mitochondrial pathways.

\section{Introduction}

In previous years, novel strategies of management for malignant cells in an integrated therapeutic manner, including surgery and radiotherapy $(1,2)$, immune therapy $(3,4)$ and chemotherapy $(5,6)$, have been investigated. Concurrently, increasing rates of chemoresistance in cancer cells against classic chemotherapy agents, including cisplatin (7), cyclophosphamide (8) and hydroxyurea (9), have been observed. Consequently, the cytotoxicity exhibited by ginkgolic acids (GAs) against malignant cells suggests that they have the potential to become a novel antitumor drug $(10,11)$.

Gas are natural components of the leaves, nuts and episperm of the Ginkgo biloba plant, and are identified in small concentrations in G. biloba cells (12). Natural GAs extracted from G. biloba are derivatives of 6-alkyl or 6-alkyl salicylic acid; the number of side chain carbon atoms in the 6th position may range from 13 to 19 , and the number of side chain double bonds may be between 0 and 3 . Therefore, the group is a mixture of homologues. Gas have been previously demonstrated to exhibit various toxicities, including allergenic (13), cytotoxic (14) and immunotoxic (13) effects. In previous decades, it has also been identified that the Gas exert antibacterial (15), insecticidal (16) and antitumor (17) effects, although the mechanism of their antitumor activity remains unclear.

Autophagy is a conserved process in cells; it supplies basic energy, and amino acids, lipids and glucose molecules for cell survival under stressful conditions including hypoxia and starvation, via the recycling of cellular components (18). Previous studies have demonstrated that autophagy can also induce apoptosis in cells $(19,20)$, yet whether autophagy is a cytotoxic $(19,20)$ or cytoprotective $(21)$ process remains unclear (22). However, a previous study indicated that autophagy is involved in the cell death process, concomitant with other well-known cell death pathways, including apoptosis and mitochondrial dysfunction $(19,20)$. A number of classical chemotherapy agents, including cisplatin (23), cyclophosphamide (24) and hydroxyurea (25), induce mitochondrial 
dysfunction and autophagy. The present study examined a potential autophagy-based anticancer strategy. GAs as novel anti-cancer agents have been indicated to induce cell apoptosis $(26,27)$, yet whether Gas induce autophagy in cells remains unclear. The present study aimed to identify whether GA-induced autophagy and mitochondrial dysfunction could also contribute to the death of cancer cells, and whether there was a cross-talk with apoptosis.

\section{Materials and methods}

Materials. The human hepatoblastoma HepG2 cell line (28) was purchased from the Cell Bank of Type Culture Collection of Chinese Academy of Sciences (Shanghai, China). MTT and dimethyl sulfoxide (DMSO) were purchased from Amresco LLC (Solon, OH, USA). 3-methyladenine (3-MA) was obtained from Sigma-Aldrich (Merck KGaA, Darmstadt, Germany). The small interfering RNA (siRNA) targeting the human Beclin-1 gene was purchased from Shanghai GenePharma Co., Ltd. (Shanghai, China). Lipofectamine ${ }^{\circledR} 2000$ was obtained from Invitrogen (Thermo Fisher Scientific, Inc., Waltham, MA, USA). The rabbit polyclonal anti-caspase-3 (cat. no. PB0183), anti-B-cell lymphoma 2 (Bcl-2; cat. no. A00040-2), anti-Bcl-2-associated X protein (Bax; cat. no. A00183) and anti-Beclin-1 antibodies (cat. no. PB0014) were purchased from Wuhan Boster Biological Technology, Ltd. (Wuhan, China). The rabbit monoclonal anti-microtubule-associated protein 1A/1B-light chain 3 (LC3; cat. no. 2057-1) antibody was obtained from Epitomics, Abcam (Cambridge, MA, USA), horseradish peroxidase (HRP)-conjugated goat anti-rabbit antibody (cat. no. CW0234S) was purchased from CWBio (http://www.cwbiotech.com/; Shanghai, China). The HRP-conjugated mouse $\beta$-actin antibody (cat. no. sc-4778) was purchased from Santa Cruz Biotechnology, Inc. (Dallas, TX, USA). The polyvinylidene difluoride (PVDF) membrane was purchased from EMD Millipore (Billerica, MA, USA). Dulbecco's modified Eagle's medium (DMEM), trypsin, and EDTA-disodium salt 2 and fetal bovine serum (FBS) were purchased from Gibco; Thermo Fisher Scientific, Inc. A Mitochondrial Transmembrane Potential $\left(\Delta \psi_{\mathrm{m}}\right)$ Analysis kit (cat. no. KGA602) was purchased from Nanjing KeyGen Biotech Co., Ltd. (Nanjing, China). All other supplies for cell culture were purchased from Corning Costar (Corning Incorporated, Corning, NY, USA).

The Gas was provided by Dr Xiaoming Yang from the School of Chemistry of Jiangsu University (Zhenjiang, China), with the purity $>98 \%$ as monitored by a high-performance liquid chromatography. The parameters of HPLC were as following, the Gas were detected by ProStar 240 (Varian Medical Systems, Inc., Palo Alto, CA, USA.) with ODS-2 (4.6*250 mm, $5 \mu \mathrm{m}$; Dalian Elite Analytical Instruments Co., Ltd., Dalian, China) at $40^{\circ} \mathrm{C}$. The sample quantity was $10 \mu \mathrm{l}$, and the composition of mobile phase was methanol-3\% HAc (92:8 v/v), the flow rate was $1.0 \mathrm{ml} / \mathrm{min}$, and the detection was by 325 type UV-detector (Varian Medical Systems, Inc.) and UV-2450 ultraviolet-visible spectrophotometer (Shimadzu Corporation, Kyoto, Japan.). Reference materials, Gas $>99 \%$, were supplied by from Dr Jaggy H of Dr Willmar Schwabe GmbH \& Co. KG, Karlsruhe Germany.
Cell culture. HepG2 cells were cultured in DMEM with $10 \%$ (v/v) FBS, $100 \mathrm{U} / \mathrm{ml}$ penicillin and $100 \mathrm{U} / \mathrm{ml}$ streptomycin at $37^{\circ} \mathrm{C}$ with $5 \% \mathrm{CO}_{2}$ and $100 \%$ humidity. When the cells reached $50-70 \%$ confluence, Gas was administered to the cells.

GA administration and MTT analysis. When the HepG2 cells were in the exponential growth phase at 50-70\% confluence, the cells were harvested and then suspended in DMEM with $5 \% \mathrm{FBS}$ at a certain concentration $\left(1 \times 10^{4}\right)$. The prepared cells were cultured in 96-well plates for $24 \mathrm{~h}$ with $10 \%$ FBS at $37^{\circ} \mathrm{C}$ and $5 \% \mathrm{CO}_{2}$. The next day, cells were incubated with various concentrations of GAs: $0,1.0625,2.125,4.25$, $8.5,17$ and $34 \mu \mathrm{g} / \mathrm{ml}$. Next, the cells were cultured for an additional $48 \mathrm{~h}$ at $37^{\circ} \mathrm{C}$. Following this, $20 \mu \mathrm{l} \mathrm{MTT}(5 \mathrm{mg} / \mu \mathrm{l})$ was administered to each well, and incubated for an additional $4 \mathrm{~h}$ at $37^{\circ} \mathrm{C}$. Subsequently, $150 \mu \mathrm{l}$ DMSO was added into each well and the cells were shaken for $10 \mathrm{~min}$. Finally, the absorbance was measured in triplicate using a standard spectrophotometer at $490 \mathrm{~nm}$. The dose-depended curve for cell inhibition was calculated based on the data obtained. Simultaneously, the cells in 10 random fields of view were observed by a light microscope (magnification, x100), and the half-maximal inhibitory concentration $\left(\mathrm{IC}_{50}\right)$ of the Gas in the HepG2 cells was calculated with the formula: $\mathrm{IC}_{50}=\lg -1[\mathrm{Xm}-\mathrm{i}(\Sigma \mathrm{P}-0.5)]$, where Xm represents the log of the max concentration of the experiment, i represents the log of each concentration measured in the experiment, $\Sigma \mathrm{P}$ denotes the sum of the rate of inhibition of each group and 0.5 is the empirical constant.

3-MA administration. When the HepG2 cells $\left(\sim 1 \times 10^{4}\right)$ were at $50-70 \%$ confluence in 6 -well plates, the cells were treated with $2.5 \mathrm{mM} 3$-MA. The next day, the Gas were added to the 3-MA-treated or negative control cells at a concentration of $20 \mu \mathrm{g} / \mathrm{ml}$ for an additional $24 \mathrm{~h}$. Next, the cells were harvested and analyzed by western blot analysis.

siRNA administration. When HepG2 cells in 6-well plates were at 50-70\% confluence, the cells were treated with $50 \mathrm{nM}$ Beclin-1-specific siRNA (Shanghai GenePharma Co., Ltd.) using Lipofectamine 2000, according to manufacturer's protocol. The sequences were as follows: Pair 1: Forward, 5'-GGAGCCAUUUAUUGAAACUTT-3' and reverse, 5'-AGU UUCAAUAAAUGGCUCCTT-3'; Pair 2: Forward, 5'-GUG GAAUGGAAUGAGAUUATT-3' and reverse, 5'-UAAUCU CAUUCCAUUCCACTT-3'; Pair 3: Forward, 5'-GCUGCC GUUAUACUGUUCUTT-3' and reverse, 5'-AGAACAGUA UAACGGCAGCTT-3'. After 24 h, Gas were administrated to the siRNA-treated or negative control cells at a concentration of $20 \mu \mathrm{g} / \mathrm{ml}$ for an additional $24 \mathrm{~h}$. Following this, the cells were harvested and analyzed by western blot analysis as described subsequently.

Western blot analysis. HepG2 cells $\left(\sim 1 \times 10^{4}\right)$ with or without Gas treatment were lysed in radioimmunoprecipitation assay lysis buffer (Beijing Solarbio Science and Technology Co., Ltd.), with a protease inhibitor cocktail, [1\% Trypsin inhibitor (Beijing Solarbio Science and Technology Co., Ltd., Beijing, China; cat. no. A8260), 1\% phosphatase inhibitor (Beijing Solarbio Science and Technology Co., Ltd.; cat. no. P1260), and 
Table I. The P-value of every two groups for Fig. 1A.

\begin{tabular}{lllllll}
\hline & 1.053 & 2.125 & 4.25 & 8.5 & 17 & 34 \\
\hline 1.053 & - & - & - & $\mathrm{P}<0.05$ & $\mathrm{P}<0.05$ & $\mathrm{P}<0.05$ \\
2.125 & - & - & - & $\mathrm{P}<0.05$ & $\mathrm{P}<0.05$ & $\mathrm{P}<0.05$ \\
4.25 & - & - & $\mathrm{P}<0.05$ & $\mathrm{P}<0.05$ & $\mathrm{P}<0.05$ \\
8.5 & $\mathrm{P}<0.05$ & $\mathrm{P}<0.05$ & $\mathrm{P}<0.05$ & - & $\mathrm{P}<0.05$ & $\mathrm{P}<0.05$ \\
17 & $\mathrm{P}<0.05$ & $\mathrm{P}<0.05$ & $\mathrm{P}<0.05$ & $\mathrm{P}<0.05$ & - & $\mathrm{P}<0.05$ \\
34 & $\mathrm{P}<0.05$ & $\mathrm{P}<0.05$ & $\mathrm{P}<0.05$ & $\mathrm{P}<0.05$ & $\mathrm{P}<0.05$ & - \\
\hline
\end{tabular}

-, no significant difference.

1\% PMSF (Beijing Solarbio Science and Technology Co., Ltd.; cat. no. P8340)], according to the protocol of the manufacturer. The protein concentration was detected by a BCA kit (Thermo Fisher Scientific, Inc.). Equivalent amounts of protein $(100 \mu \mathrm{g})$ from every sample were separated by $10 \%$ SDS-PAGE, then separated by electrophoresis, and then transferred to a PVDF membrane. Next, the membrane was blocked with $5 \%$ bovine serum albumin in TBS (Gibco; Thermo Fisher Scientific, Inc.) for $2 \mathrm{~h}$ at $37^{\circ} \mathrm{C}$. The membrane was incubated at $37^{\circ} \mathrm{C}$ for $2 \mathrm{~h}$ with primary antibodies (dilutions, 1:200) against the specific proteins, and then incubated with HRP-conjugated secondary antibodies (dilutions, $1: 5,000$ ) at $37^{\circ} \mathrm{C}$ for $2 \mathrm{~h}$. The membranes were then washed 3 times for $10 \mathrm{~min}$ each. Then, the protein bands were scanned using a Typhoon 9400 Variable Mode Imager (Amersham; GE Healthcare, Chicago, IL, USA) and detected using Pierce Electrochemiluminescence Plus Substrate (Thermo Fisher Scientific, Inc.). The software used for densitometric analysis was Lane 1D (version 4.0.00.001; Beijing Sage Creation Science Co., Ltd).

$\Delta \psi_{m}$ analysis. The $\Delta \psi_{\mathrm{m}}$ of HepG2 cells was detected using JC-1 dye. HepG2 cells $\left(\sim 1 \times 10^{4}\right)$ were incubated in 24 -well plates, and treated with Gas at a concentration of $20 \mu \mathrm{g} / \mathrm{ml}$ for $24 \mathrm{~h}$. Next, following the JC-1 manufacturer's protocol $(2.5 \mu \mathrm{g} / \mathrm{ml}$ at $37^{\circ} \mathrm{C}$ for $30 \mathrm{~min}$; Nanjing KeyGen Biotech Co., Ltd.), the cells were stained. The cells were monitored by fluorescence microscopy (magnification, x200).

Terminal deoxynucleotidyl-transferase-mediated dUTP nick-end labeling (TUNEL) assay. The HepG2 cells $\left(\sim 1 \times 10^{4}\right)$ were treated with Gas at a concentration of $20 \mu \mathrm{g} / \mathrm{ml}$ in the logarithmic growth phase for $24 \mathrm{~h}$, and then fixed with $4 \%$ paraformaldehyde at $37^{\circ} \mathrm{C}$ for $24 \mathrm{~h}$. Next, following to the protocol of the manufacturer of the TUNEL kit (cat. no. KGA702; Nanjing KeyGen Biotech Co., Ltd.), these cells were stained and monitored by a microscope. The mounting medium used was glycerol, and the cells in 10 random fields of view were observed with a light microscope (magnification, $\mathrm{x} 200)$.

Statistical analysis. Data are presented as the mean \pm standard deviation. Data analyses were performed using one-way analysis of variance with Student Newman-Keuls post-hoc test (>3 groups) or Student's t-test (two groups) in SPSS v.23 software (IBM Corp., Armonk, NY, USA). P $<0.05$ was considered to indicate a statistically significant difference. All experiments were repeated at least 3 times.

\section{Results}

GAs inhibitcells proliferation. The dose-dependent curves for GAs in HepG2 cells were measured by MTT assay following $24 \mathrm{~h}$ Gas treatment. HepG2 cell viability decreased with the increases in GAs concentration and incubation time. When the cells were treated with GAs, the optical density (OD), increased in the GAs treatment groups as the GAs concentration decreased, and at the $4.25 \mu \mathrm{g} / \mathrm{ml}$, the dose-depended curve reached the threshold $(4.25 \mu \mathrm{g} / \mathrm{ml})$ compared with the control group. Next, the inhibition ratio of the GAs increased significantly $(\mathrm{P}<0.05$, Table I). Simultaneously, the inhibition rate also increased over time following Gas treatment. Therefore, the inhibition rate caused by GAs was time- and dose-dependent. The OD values of the HepG2 cells treated with GAsfor 24 hare depicted in Fig. 1A. Using the formula $\mathrm{IC}_{50}=\lg -1[\mathrm{Xm}-\mathrm{i}(\Sigma \mathrm{P}-0.5)]$, where $\mathrm{Xm}$ denotes the $\log$ of the max concentration of the experiment, $i$ represents the log of each concentration measured in the experiment, $\Sigma \mathrm{P}$ represents the sum of the rate of inhibition of each group and the 0.5 is an empirical constant, the $\mathrm{IC}_{50}$ of Gas was calculated to be $25 \mu \mathrm{g} / \mathrm{ml}$. Additionally, the morphological changes in the treatment cells were monitored by microscopy. As depicted in Fig. 1B, an increased number of cells in the GAs treatment group exhibited an increased rate greater number of characteristic vacuolation compared with the control group.

GAs induce apoptosis in HepG2 cells. The TUNEL assay was used to monitor the apoptosis in HepG2 cells (Fig. 2A). The level of apoptosis in the GA groups was markedly increased compared with the control group $(\mathrm{P}<0.05)$. Apoptosis of the HepG2 cells was also monitored by western blotting analysis. The expression levels of the apoptosis-associated proteins caspase-3, Bcl-2 and Bax in the HepG2 cells were detected at $24 \mathrm{~h}$ after GA treatment. The expression levels of caspase-3, Bax and $\mathrm{Bcl}-2$ were increased in the GA-treated groups compared with the control group $(\mathrm{P}<0.05)$; whereas the $\mathrm{Bax} / \mathrm{Bcl}-2$ ratio exhibited a peak when the concentration of GAs was $20 \mu \mathrm{g} / \mathrm{ml}$ (Fig. 2B and C). And the number of apoptotic cells in the GAs groups was increased, compared with that in the control group $(\mathrm{P}<0.05)$, as demonstrated in Fig. $2 \mathrm{C}$ 
A

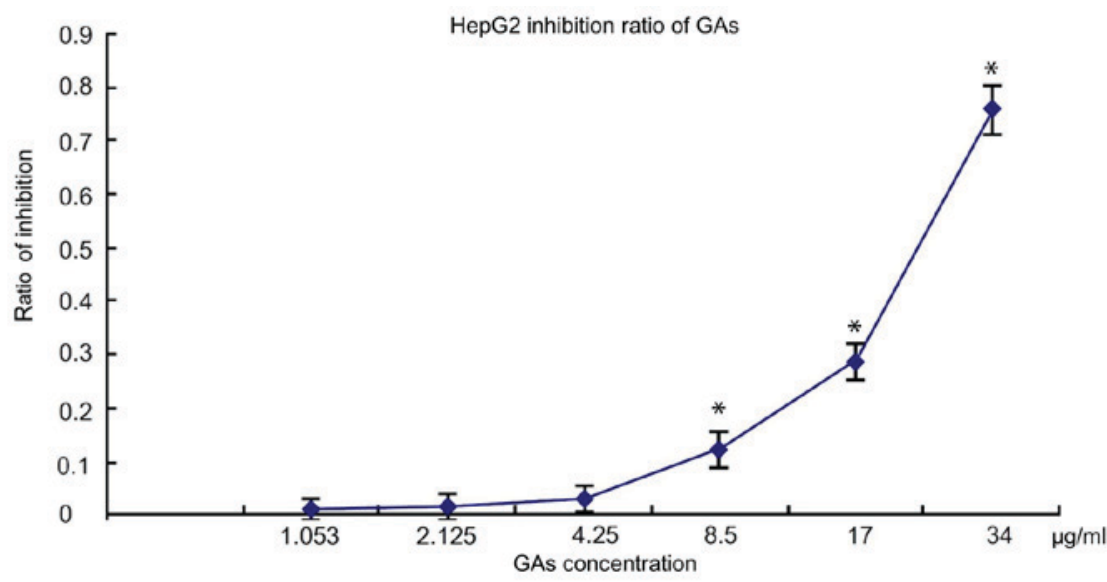

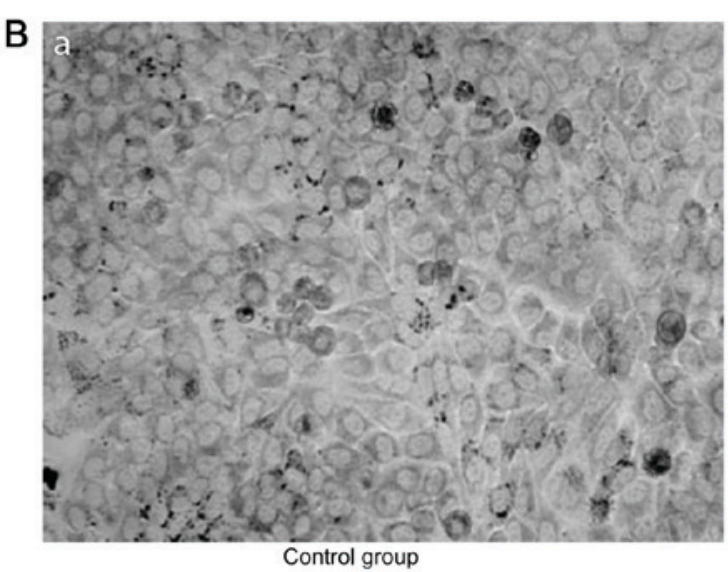

Figure 1. GAs inhibit HepG2 cells proliferation. (A) Dose-depended curve of HepG2 cells following treatment with Gas for $24 \mathrm{~h}$. The cells treated with Gas for $24 \mathrm{~h}$ exhibited a significantly increased level of inhibition of HepG2 cells compared with the control group ( $\mathrm{P}<0.05$ vs. control group). (B) Images of HepG2 cells treated with GAs at $24 \mathrm{~h}$ captured by light microscopy (magnification, $\mathrm{x} 200$ ). (Ba) control group and (Bb) HepG2 cells treated with GAs. The cells treated with Gas were decreased in size compared with those in the control group. GAs, ginkgolic acids (the P-value of each two groups depicted in Table I).
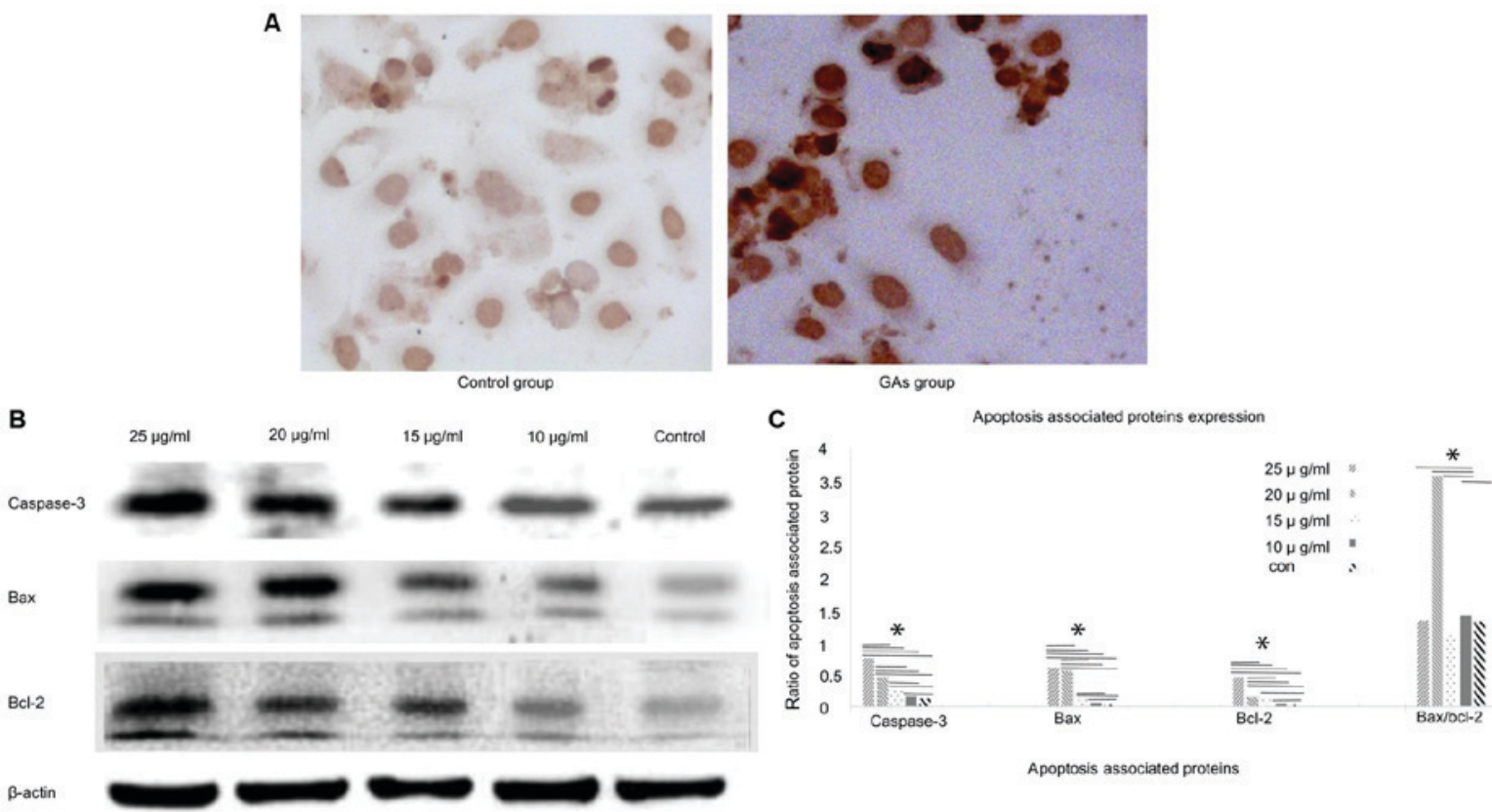

Figure 2. Apoptosis and its associated proteins expression levels in HepG2 cells at $24 \mathrm{~h}$ following treatment with GAs. (A) Apoptosis of GAs-treated cells, as measured by terminal deoxynucleotidyl-transferase-mediated dUTP nick-end labeling staining. The proportion of apoptotic GA-treated cells was markedly higher than the control-treated cells. (B) The expression of apoptosis-associated proteins in HepG2 cells was detected by western blot analysis. The expression of caspase-3, Bax, and Bcl-2 in the GA-treated groups (various concentrations) was increased compared with that in the control group, and the caspase-3, Bax and $\mathrm{Bcl}-2$ protein expression levels increased as the concentration of Gas increased. The Bax/Bcl-2 ratio reached its peak in the $20 \mu \mathrm{g} / \mathrm{ml} \mathrm{group}$, which was close to the median lethal dose of GAs. (C) Quantification of the apoptosis-associated proteins bands in (B) ( $\mathrm{P}<0.05)$. GAs, ginkgolic acids; Bcl-2, B-cell lymphoma 2; Bax, Bcl-2-associated X protein. 


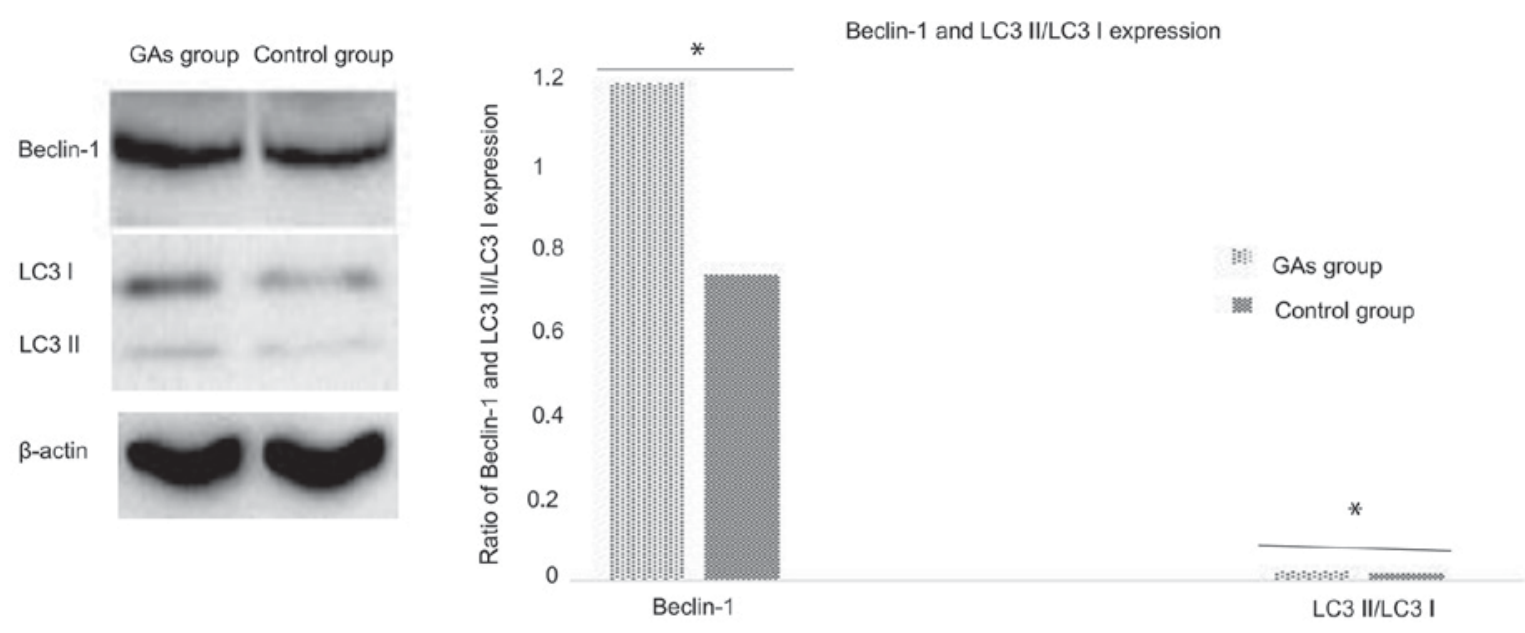

Figure 3. Gas induce autophagy inHepG2 cells. The expression of the autophagy-associated proteins Beclin-1 and LC3 in the GAs group significantly differed compared with that of the control group ( $\mathrm{P}<0.05)$. GAs, ginkgolic acids; LC3, microtubule-associated proteins 1A/1B light chain 3 .

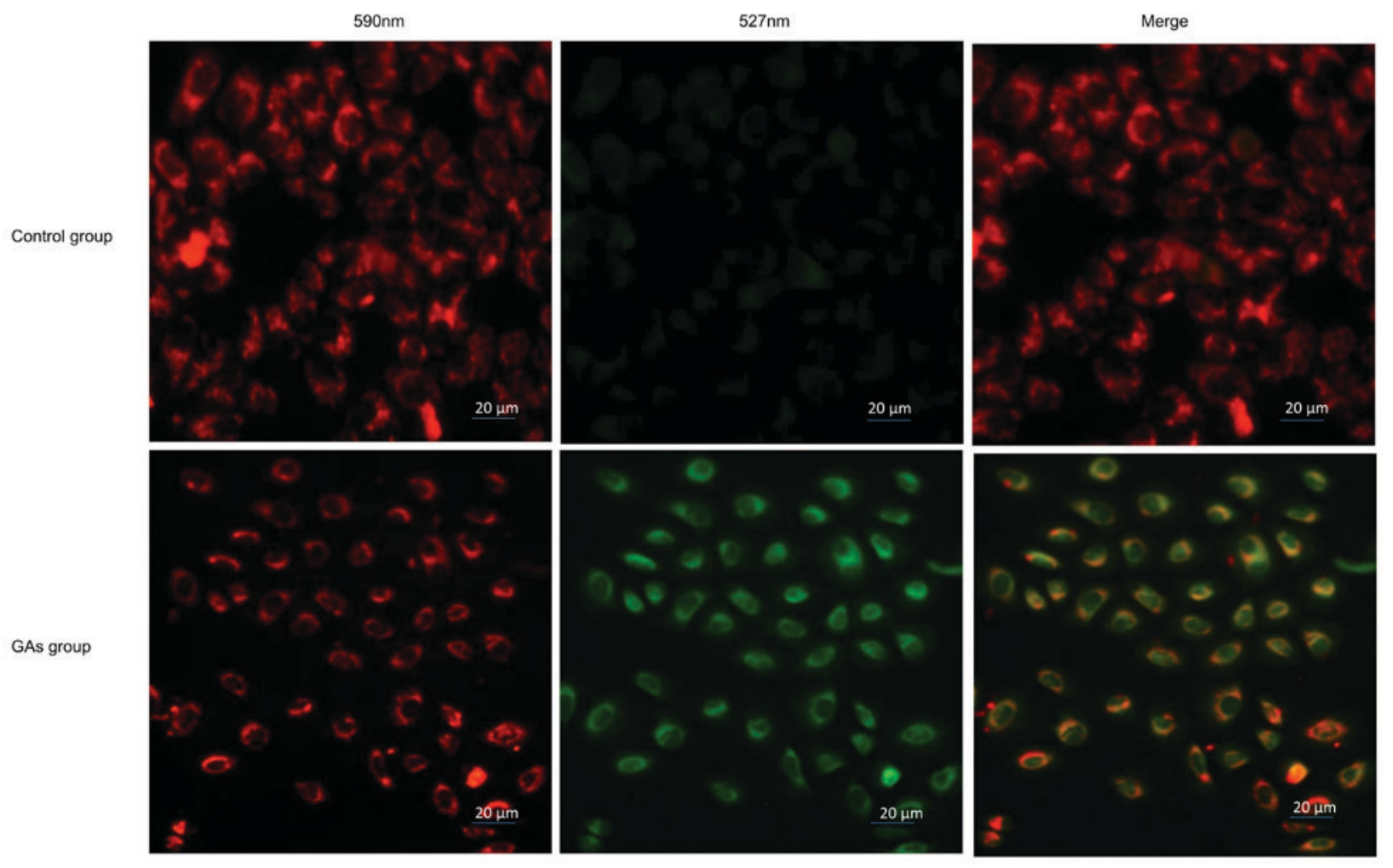

Figure 4. GAs induced a decrease in the mitochondrial membrane potential of HepG2 cells. An increased number of dysfunctional mitochondria were present in the group treated with Gas compared with the control group. GAs, ginkgolic acids.

GAs induce HepG2 cell autophagy. As the GA-treated HepG2 cells exhibited morphological changes such as vacuolization, it may be that autophagy is involved in this process. The autophagy activity of cells with or without administration of Gas was detected. The ratio of LC3-II/ LC3-I is a good indicator of autophagy activity (29), and in the preliminary experiments of the present study, it was identified that it took $\sim 24 \mathrm{~h}$ for significant evidence of vacuolization following treatment of the HepG2 cells with $20 \mu \mathrm{g} / \mathrm{ml} \mathrm{GAs}$ (data not shown). Therefore, $12 \mathrm{~h}$ was the time-point used for the routine measurement of autophagy. In addition to monitoring the ratio of LC3-II to LC3-I in the cells at $12 \mathrm{~h}$ following GAs administration, the Beclin-1 protein level was also analyzed as an additional autophagy marker. As depicted in Fig. 3, the expression of the autophagy-associated proteins Beclin-1 and LC3 in the HepG2 cells of the GA-treated group was significantly higher than in the control groups $(\mathrm{P}<0.05)$.

GAs induce mitochondrial dysfunction in HepG2 cells. Mitochondria are involved in apoptosis (30); therefore, the $\Delta \psi_{\mathrm{m}}$ of the $20 \mu \mathrm{g} / \mathrm{ml}$ GA-treated HepG2 cells and the control HepG2 cells was monitored using JC-1 staining. If the cells 
A
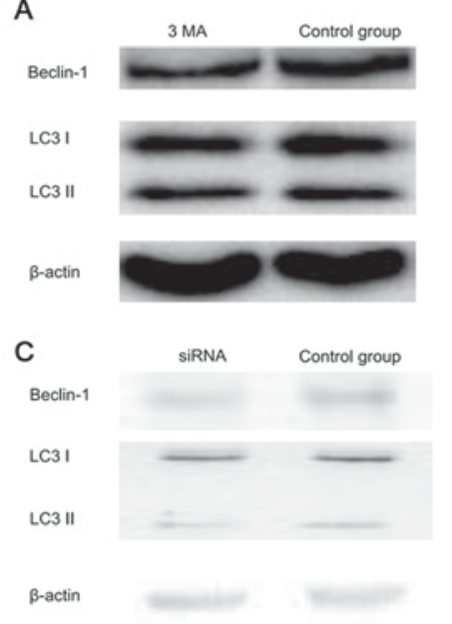
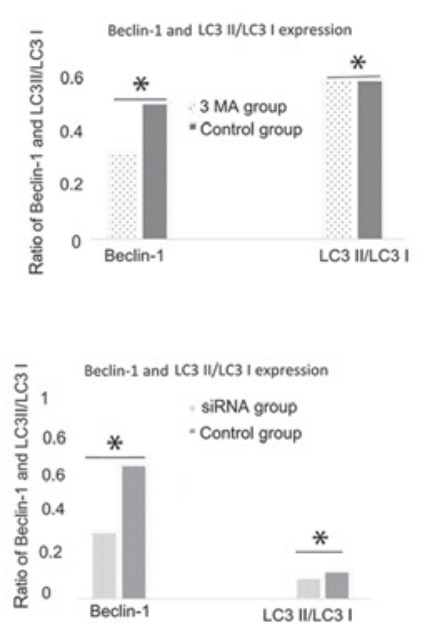

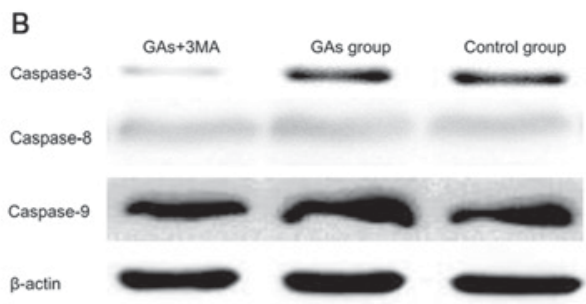

Apoptosis associated proteins expression
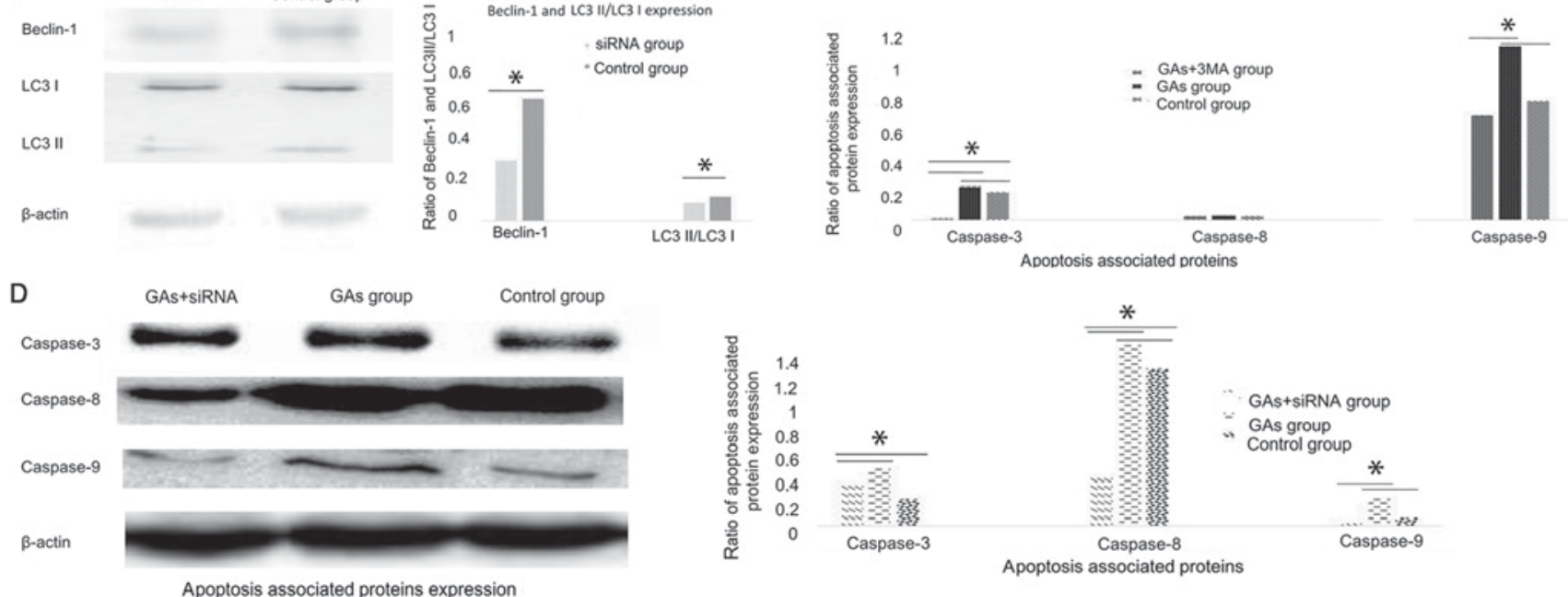

Figure 5. Down regulation of autophagy contributes to alterations in the expression of apoptosis-associated proteins in HepG2 cells following decreasing treatment with GAs. (A) Expression of autophagy-associated proteinsBeclin-1 and LC3 following3-MA treatment. The expression levels of the autophagy-associated proteins Beclin-1 and LC3 were decreased in the cells that underwent3-MA treatment compared with the control group ( $\left.{ }^{*} \mathrm{P}<0.05\right)$. (B) The expression of the apoptosis-associated proteins caspase- 3 and-9 in the GAs group was increased compared with the GAs+3-MA group and the control group ("P $<0.05$; the P-value of each two groups are depicted in Table II). (C) Expression of autophagy-associated protein Beclin-1 and LC3 following siRNA treatment. The expression levels of the autophagy-associated proteins Beclin-1 and LC3 were decreased in cells following siRNA treatment, compared with the control group ("P $\mathrm{P}$ 0.05). (D) The expression of apoptosis-associated proteins caspase-3, -8 and -9 in the GAs group increased compared with those in the GAs+siRNA group or the control group ("P<0.05; the P-value of each two groups are depicted in Table III). GAs, ginkgolic acids; LC3, microtubule-associated protein 1A/1B-light chain 3; 3-MA, 3-Methyladenine; siRNA, small interfering RNA.

exhibited an increase in the intensity of green staining compared with red, this indicated an increased number of dysfunctional mitochondria. It was observed that the green fluorescence intensity increased and the red fluorescence intensity decreased in the cells treated with GAs. The ratio of red to green was significantly decreased in the GAs-treated group compared with the control group $(\mathrm{P}<0.05)$, as indicated in Fig. 4.

Autophagy contributes to HepG2 cells apoptosis introduced by GAs. Numerous studies have demonstrated that autophagy can be cytoprotective $(18,21)$ and cytotoxic $(19,20)$ activities. To investigate whether autophagy was involved in the apoptosis process induced by GAs in HepG 2 cells, and whether its activity was cytoprotective or cytotoxic, the autophagy inhibitor 3-MA was administered to the GA-treated HepG2 cells. Then, the autophagy-associated protein Beclin-1 was detected, and it was demonstrated that the level of autophagy in the GA-treated HepG2 cells was inhibited $(\mathrm{P}<0.05)(31,32)$, as indicated in Fig. 5A. The expression levels of the apoptosis-associated proteins caspases-3, -8 and 9 were monitored, and the results revealed that they were all decreased in the 3-MA-treated GAs HepG2 group compared with the GAs HepG2 group without 3-MA treatment $(\mathrm{P}<0.05$, Table II), as indicated Fig. 5B. As 3-MA is a non-specific autophagy suppressor (33), the Class III phosphoinositide 3-kinase (PI3K-III), an autophagy inducer, and PI3K-I, an autophagy suppressor, pathways were inhibited by 3 -MA. The autophagy regulator Beclin-1 was silenced to additionally confirm the results of the 3-MA treatment assay. The efficacy of the siRNA in the HepG2 cells was initially detected by western blot analysis (Fig. 5C). The Beclin-1 protein expression level was decreased significantly in HepG2 cells upon Beclin-1 siRNA treatment $(\mathrm{P}<0.05)$. Subsequently, the levels of caspase-3, -8 and -9 in the Beclin-1-silenced HepG2 cells treated with GAs was monitored, and the results confirmed those of the 3-MA treatment experiment, which were that when the rate of autophagy was decreased, the level of apoptosis was decreased ( $\mathrm{P}<0.05$, Table III; Fig. 5D).

\section{Discussion}

In previous decades, increasing levels of chemotherapy resistance in cancer have been described $(34,35)$. Therefore, an integrated management system for malignant tumors, which includes surgery and radiotherapy $(1,2)$, gene therapy (36) and immune therapy (3), has become a reasonable therapeutic strategy. One potential strategy to overcome resistance is the use of novel antitumor drugs that interact with traditional or novel targets; Gas represent one such class of these potential therapeutics. 
Table II. The P-value of every two groups for Fig. 5B.

\begin{tabular}{llll}
\hline & GAs+3-MA & GAs & Control group \\
\hline Caspase3 & & & P \\
GAs+3-MA & - & - & P \\
GAs & P $<0.05$ & P $<0.05$ & P $<0.05$ \\
Control group & P $<0.05$ & GAs & - \\
Caspase-8 & GAs+3-MA & - & Control group \\
GAs+3-MA & - & - & - \\
GAs & - & - & - \\
Control group & - & GAs & Control group \\
Caspase-9 & GAs+3-MA & P $<0.05$ & - \\
GAs+3-MA & - & - & P $<0.05$ \\
GAs & P $<0.05$ & P $<0.05$ & - \\
Control group & - & & \\
\hline
\end{tabular}

-, no significant difference; GAs, ginkgolic acids; 3-MA, 3-Methyladenine.

Table III. The P-value of every two groups for Fig. 5D.

\begin{tabular}{llll}
\hline & GAs+siRNA & GAs & Control group \\
\hline Caspase3 & & & \\
GAs+siRNA & - & $\mathrm{P}<0.05$ & $\mathrm{P}<0.05$ \\
GAs & $\mathrm{P}<0.05$ & - & - \\
Control group & $\mathrm{P}<0.05$ & - & - \\
Caspase-8 & GAs+siRNA & $\mathrm{GAs}$ & $\mathrm{C}$ - 0 trol group \\
GAs+siRNA & - & $\mathrm{P}<0.05$ & $\mathrm{P}<0.05$ \\
GAs & $\mathrm{P}<0.05$ & - & $\mathrm{P}<0.05$ \\
Control group & $\mathrm{P}<0.05$ & & - \\
Caspase-9 & $\mathrm{GAs}+\mathrm{siRNA}$ & $\mathrm{GAs}$ & $\mathrm{C}$ Control group \\
GAs+siRNA & - & $\mathrm{P}<0.05$ & - \\
GAs & $\mathrm{P}<0.05$ & - & $\mathrm{P}<0.05$ \\
Control group & - & $\mathrm{P}<0.05$ & - \\
\hline
\end{tabular}

-, no significant difference; GAs, ginkgolic acids; siRNA, small interfering RNA.

GAs have been used previously as antitumor agents in preclinical studies $(14,37)$. Its potential application as an anti-cancer drug is due to its effects on tumor cell apoptosis (38), and previous studies have indicated that Gas exhibit marked antitumor potency. In the present study, multiple mechanisms of GAs-induced cytotoxicity were elucidated, including mitochondria land apoptotic pathways.

To the best of our knowledge, the present study demonstrated for the first time that autophagy is activated in the Gas-treated HepG2 cells, and that potential crosstalk exists between apoptosis and autophagy, in gastric carcinoma cells exposed to GAs. This result is supported by the following observations: Firstly, morphological changes in theHepG2 cells treated with Gas indicated vacuolization (39); secondly, LC3-II/LC3-I are molecular chaperones in autophagy that are involved with autophagy membrane elongation and closure (40), and when HepG2 cells were infected with GAs in the present study, the expression level of LC3-II/LC3-I was significantly increased; thirdly, suppression of autophagy by the chemical 3-MA reduced the levels of GAs-induced autophagy and apoptosis; fourthly, knockdown of Beclin-1 with a specific siRNA decreased the GA-induced LC3-II conversion and the expression of caspase-3, -8 and-9, indicating that the induction of autophagy may result in crosstalk with apoptosis in the GAs-treated HepG2 cells. In addition, it was observed that the mitochondrial pathway was involved in the GA-induced HepG2 cell death, as the $\Delta \psi_{\mathrm{m}}$ decreased in the Gas-treated cells in comparison with the control group These experimental data indicate that the induction of HepG2 cell death was a net effect of the autophagy, mitochondrial and apoptosis pathways. Autophagy triggers apoptosis through the Beclin-1-mediated down regulation of Bcl-2 (41). In previous decades, a number of studies have demonstrated that Bcl-2 is involved in apoptosis and autophagy (30,42-44). Beclin-1 is considered to be a member of the Bcl-2 family as it also contains an N-terminal BH3 domain, and contributes to the activity of Bcl-2 and Bcl-extra large, and inhibits the formation of the autophagosome $(44,45)$. In the present study, western blot analysis revealed that the expression of Beclin-1 increased in GA-treated HepG 2 cells in comparison with the control group, and therefore the interaction between Beclin-1 and Bcl-2 decreased, promoting autophagy and apoptosis. In the present study, knockdown of Beclin-1 using the Beclin-1-specific siRNA suppressed the conversion of LC3-I to LC-II, but also decreased caspase-3 protein expression. Consequently, crosstalk between autophagy and apoptosis may have occurred.

It has been demonstrated that the calmodulin proteins, calpains, degrade autophagy protein 5 (ATG-5), which is involved in the autophagy pathway (46). The cleavage of ATG-5 may anchor an amino-terminal production of ATG-5 cleaved by calpain to the mitochondria, causing the release of cytochrome $\mathrm{c}$ and followed by mitochondrial dysfunction. In the present study, treatment with GAs caused a reduction 
in HepG2 cell mitochondrial trans-membrane potential, demonstrating that mitochondrial dysfunction contributed to GA-induced HepG2 cell death by increasing mitochondrial permeability transition and generating reactive oxygen species. It is also known that mitochondria may introduce apoptosis via the intrinsic pathway (47). Therefore, we hypothesized that treatment with GAs induced HepG2 cell apoptosis via the mitochondrial, apoptosis and autophagy and pathways.

In conclusion, the results of the present study indicated that treatment with Gas induced HepG2 cell death via apoptosis, autophagy and/or mitochondrial pathways. Although the association between autophagy, apoptosis and mitochondrial dysfunction remains unclear, Gas may represent a powerful drug candidate for antitumor therapy.

\section{Acknowledgements}

Not applicable.

\section{Funding}

No funding was received.

\section{Availability of data and materials}

The datasets used and/or analyzed during the current study are available from the corresponding author on reasonable request.

\section{Authors' contributions}

QMQ cultured the cells and interpreted the effects of 3-MA and siRNA administration, and was a major contributor in writing the manuscript. YCX, JL, DS and JXD performed the western blotting, and monitored apoptosis and autophagy. SQC, YHL and TCG performed the JC-1 experiments. MBW analyzed and interpreted all the data, and designed the study. All authors read and approved the final manuscript.

\section{Ethics approval and consent to participate}

Not applicable.

\section{Consent for publication}

Not applicable.

\section{Competing interests}

The authors declare that they have no competing interests.

\section{References}

1. Shimizuguchi T, Nihei K, Okano T, Machitori Y, Ito K and Karasawa K: A comparison of clinical outcomes between three-dimensional conformal radiotherapy and intensity-modulated radiotherapy for prostate cancer. Int J Clin Oncol 22: 373-379, 2017.

2. Verma V, Moreno AC and Lin SH: Advances in radiotherapy management of esophageal cancer. J Clin Med 5: pii: E91, 2016.

3. Yang Y, Hu Y and Wang H: Targeting antitumor immune response for enhancing the efficacy of photodynamic therapy of cancer: Recent advances and future perspectives. Oxid Med Cell Longev 2016: 5274084, 2016.
4. Yeku O and Slovin SF: Immune therapy for prostate cancer. Cancer J 22: 334-341, 2016.

5. Friese CR, Li Y, Bondarenko I, Hofer TP, Ward KC, Hamilton AS Deapen D, Kurian AW and Katz SJ: Chemotherapy decisions and patient experience with the recurrence score assay for early-stage breast cancer. Cancer 123: 43-51, 2017.

6. Lohiya V, Aragon-Ching JB and Sonpavde G: Role of chemotherapy and mechanisms of resistance to chemotherapy in metastatic castration-resistant prostate cancer. Clin Med Insights Oncol 10 (Suppl 1): S57-S66, 2016.

7. Sun Y, Guan Z, Liang L, Cheng Y, Zhou J, Li J and Xu Y: NF-кB signaling plays irreplaceable roles in cisplatin-induced bladder cancer chemoresistance and tumor progression. Int J Oncol 48: 225-234, 2016.

8. Hsu YL, Hung JY, Tsai EM, Wu CY, Ho YW, Jian SF, Yen MC, Chang WA, Hou MF and Kuo PL: Benzyl butyl phthalate increases the chemoresistance to doxorubicin/cyclophosphamide by increasing breast cancer-associated dendritic cell-derivedCXCL1/ GROalpha and S100A8/A9. Oncol Rep 34: 2889-2900, 2015.

9. Thoenes L, Hoehn M, Kashirin R, Ogris M, Arnold GJ, Wagner E and Guenther M: In vivo chemoresistance of prostate cancer in metronomic cyclophosphamide therapy. J Proteomics 73: 1342-1354, 2010.

10. Oh J, Hwang IH, Hong CE, Lyu SY and Na M: Inhibition of fatty acid synthase by ginkgolic acids from the leaves of Ginkgo biloba and their cytotoxic activity. J Enzyme Inhib Med Chem 28: 565-568, 2013.

11. Wang H, Zhou CC, Feng Y, Dai LN, Chen J, Chen SX, Li XY, Liu YR and Zhang P: The effect of ginkgolic acids on multidrug resistance in oral squamous cell carcinoma. Hua Xi Kou Qiang Yi Xue Za Zhi 28: 668-671, 2010 (In Chinese).

12. Fuzzati N, Pace R and Villa F: A simple HPLC-UV method for the assay of ginkgolic acids in Ginkgo biloba extracts. Fitoterapia 74: 247-256, 2003.

13. Long R, Yin R and Zhen Y: Partial purification and analysis of allergenicity, immunogenicity of Ginkgo biloba L. pollen. Hua Xi Yi Ke Da Xue Xue Bao 23: 429-432, 1992 (In Chines).

14. Chao JC and Chu CC: Effects of Ginkgo biloba extract on cell proliferation and cytotoxicity in human hepatocellular carcinoma cells. World J Gastroenterol 10: 37-41, 2004.

15. Lee JH, Kim YG, Ryu SY, Cho MH and Lee J: Ginkgolic acids and Ginkgo biloba extract inhibit Escherichia coli O157:H7 and Staphylococcus aureus biofilm formation. Int J Food Microbiol 174: 47-55, 2014.

16. Thompson AJ, McGonigle I, Duke R, Johnston GA and Lummis SC: A single amino acid determines the toxicity of Ginkgo biloba extracts. FASEB J 26: 1884-1891, 2012.

17. Ma J, Duan W, Han S, Lei J, Xu Q, Chen X, Jiang Z, Nan L, Li J, Chen K, et al: Ginkgolic acid suppresses the development of pancreatic cancer by inhibiting pathways driving lipogenesis. Oncotarget 6: 20993-21003, 2015.

18. Klionsky DJ and Emr SD: Autophagy as a regulated pathway of cellular degradation. Science 290: 1717-1721, 2000.

19. Bu X, Zhao Y, Zhang Z, Wang M, Li M and Yan Y: Recombinant Newcastle disease virus (rL-RVG) triggers autophagy and apoptosis in gastric carcinoma cells by inducing ER stress. Am J Cancer Res 6: 924-936, 2016.

20. Bu XF, Wang MB, Zhang ZJ, Zhao YH, Li M and Yan YL: Autophagy is involved in recombinant Newcastle disease virus (rL-RVG)-induced cell death of stomach adenocarcinoma cells in vitro. Int J Oncol 47: 679-689, 2015.

21. Kania E, Pajak B, O'Prey J, Sierra Gonzalez P, Litwiniuk A, Urbańska K, Ryan KM and Orzechowski A: Verapamil treatment induces cytoprotective autophagy by modulating cellular metabolism. FEBS J 284: 1370-1387, 2017.

22. Anding AL and Baehrecke EH: Autophagy in cell life and cell death. Curr Top Dev Biol 114: 67-91, 2015.

23. Lee YJ, Lee GJ, Yi SS, Heo SH, Park CR, Nam HS, Cho MK and Lee SH: Cisplatin and resveratrol induce apoptosis and autophagy following oxidative stress in malignant mesothelioma cells. Food Chem Toxicol 97: 96-107, 2016.

24. Kumari KK and Setty OH: Protective effect of Phyllanthus fraternus against mitochondrial dysfunction induced by co-administration of cisplatin and cyclophosphamide. J Bioenerg Biomembr 44: 179-188, 2012.

25. Hackenberg T, Juul T, Auzina A, Gwizdz S, Malolepszy A, Van Der Kelen K, Dam S, Bressendorff S, Lorentzen A, Roepstorff $\mathrm{P}$, et al: Catalase and NO CATALASE ACTIVITY1 promote autophagy-dependent cell death in Arabidopsis. Plant Cell 25: 4616-4626, 2013 
26. Yang XM, Wang YF, Li YY and Ma HL: Thermal stability of ginkgolic acids from Ginkgo biloba and the effects of ginkgol C17:1 on the apoptosis and migration of SMMC7721 cells. Fitoterapia 98: 66-76, 2014

27. Zhou C, Li X, Du W, Feng Y, Kong X, Li Y, Xiao L and Zhang P: Antitumor effects of ginkgolic acid in human cancer cell occur via cell cycle arrest and decrease the $\mathrm{Bcl}-2 / \mathrm{Bax}$ ratio to induce apoptosis. Chemotherapy 56: 393-402, 2010.

28. López-Terrada D, Cheung SW, Finegold MJ and Knowles BB Hep G2 is a hepatoblastoma-derived cell line. Hum Pathol 40 $1512-1515,2009$.

29. Schaaf MB, Keulers TG, Vooijs MA and Rouschop KM: LC3/GABARAP family proteins: Autophagy-(un)related functions. FASEB J 30: 3961-3978, 2016.

30. Qi Z, Dong W, Shi W, Wang R, Zhang C, Zhao Y, Ji X, Liu KJ and Luo Y: Bcl-2 phosphorylation triggers autophagy switch and reduces mitochondrial damage in limb remote ischemic conditioned rats after ischemic stroke. Transl Stroke Res 6: 198-206, 2015.

31. Münz C: Autophagy proteins in phagocyte endocytosis and exocytosis. Front Immunol 8: 1183, 2017.

32. Nascimbeni AC, Codogno P and Morel E: Phosphatidylinositol-3phosphate in the regulation of autophagy membrane dynamics. FEBS J 284: 1267-1278, 2017.

33. Lemasters JJ: Variants of mitochondrial autophagy: Types 1 and 2 mitophagy and micromitophagy (Type 3). Redox Biol 2 : 749-754, 2014

34. Kim J and Hurria A: Determining chemotherapy tolerance in older patients with cancer. J Natl Compr Canc Netw 11: 1494-1502, 2013

35. Kalsi T, Babic-Illman G, Ross PJ, Maisey NR, Hughes S, Fields P, Martin FC, Wang Y and Harari D: The impact of comprehensive geriatric assessment interventions on tolerance to chemotherapy in older people. Br J Cancer 112: 1435-1444, 2015.

36. Lara-Guerra $\mathrm{H}$ and Roth JA: Gene therapy for lung cancer. Crit Rev Oncog 21: 115-124, 2016.

37. Yang X, Qian Z, Chen J, Zhu W and Xie J: Study on antitumor activities of ginkgolic acids from Ginkgo sarcotestas in vitro. Zhong Yao Cai 27: 40-42, 2004 (In Chinese).
38. Zhou CC, Du W, Wen Z, Li JY and Zhang P: Effects of natural plant ginkgolic acids on the apoptosis of human Hep-2 cancer cells. Sichuan Da Xue Xue Bao Yi Xue Ban 40: 459-461, 2009 (In Chinese)

39. Klionsky DJ, Abeliovich H, Agostinis P, Agrawal DK, Aliev G, Askew DS, Baba M, Baehrecke EH, Bahr BA, Ballabio A, et al: Guidelines for the use and interpretation of assays for monitoring autophagy in higher eukaryotes. Autophagy 4: 151-175, 2008

40. Wesselborg S and Stork B: Autophagy signal transduction by ATG proteins: From hierarchies to networks. Cell Mol Life Sci 72: 4721-4757, 2015

41. Hetz C: The unfolded protein response: Controlling cell fate decisions under ER stress and beyond. Nat Rev Mol Cell Biol 13: 89-102, 2012.

42. Levine B, Sinha SC and Kroemer G: Bcl-2 family members: Dual regulators of apoptosis and autophagy. Autophagy 4: 600-606, 2008.

43. Kale J, Osterlund EJ and Andrews DW: BCL-2 family proteins: Changing partners in the dance towards death. Cell Death Differ 25: 65-80, 2018

44. Pattingre S, Tassa A, Qu X, Garuti R, Liang XH, Mizushima N, Packer M, Schneider MD and Levine B: Bcl-2 antiapoptotic proteins inhibit Beclin 1-dependent autophagy. Cell 122: 927-939, 2005

45. Lomonosova $\mathrm{E}$ and Chinnadurai G: $\mathrm{BH} 3$-only proteins in apoptosis and beyond: An overview. Oncogene 27 (Suppl 1): S2-S19, 2008

46. Yousefi S, Perozzo R, Schmid I, Ziemiecki A, Schaffner T, Scapozza L, Brunner T and Simon HU: Calpain-mediated cleavage of Atg 5 switches autophagy to apoptosis. Nat Cell Biol 8: 1124-1132, 2006.

47. Gong A, Ye S, Xiong E, Guo W, Zhang Y, Peng W, Shao G, Jin J, Zhang Z, Yang J and Gao J: Autophagy contributes to ING4-induced glioma cell death. Exp Cell Res 319: 1714-1723, 2013. 